Jonathan Morris

\title{
The influence of social factors on minority language engagement amongst young people: an investigation of Welsh-English bilinguals in North Wales
}

\begin{abstract}
The majority of young Welsh speakers now come from English-speaking homes and reside in communities where English is the dominant language (Jones 2008: 550; Jones 2012: 6). Previous studies have shown, however, that these speakers use Welsh less than those from Welsh-speaking homes in Welshdominant communities (Jones 2008: 553). This article examines the correlation between speakers' backgrounds and their language attitudes, self-confidence in their language skills and use of Welsh. Both quantitative and qualitative data were collected from 27 participants from two cohorts of Welsh-medium Sixth Form units in a Welsh-dominant area of North West Wales and an Englishdominant area of North East Wales. While attitudes towards Welsh were generally positive, those from English-speaking homes feel less confident in their Welsh in both areas. The use of Welsh amongst those from English-speaking homes is also relatively low regardless of the dominant language of the community. Amongst those from Welsh-speaking homes, use is significantly lower amongst those who reside in the North East. It is suggested that these results are attributable to peer-group dynamics in the two areas: in the North West, language-specific peer groups were found whereas English was the language of all peer groups in the North East.
\end{abstract}

Keywords: Welsh-medium education, Welsh-English bilingualism, language attitudes, language planning, immersion education

\section{Introduction}

The majority of Welsh-English bilinguals now acquire Welsh through immersion education rather than via parental transmission (Jones 2008: 550). Such "new

Jonathan Morris: Cardiff University. E-mail: Morrisj17@cardiff.ac.uk 
speakers" mostly come from areas where Welsh is not a dominant community language, though many children living in Y Fro Gymraeg or Welsh-speaking heartland areas also speak only English at home (Jones 2012: 15). Consequently, two independent distinctions can be made based on a speaker's home language and whether they live in a Welsh-dominant or English-dominant area. Studies of large-scale data have shown that these factors correlate with language use, with Welsh being more likely to be used on a daily basis by those who both come from Welsh-speaking homes and live in areas where over $60 \%$ of the population speak the language (Jones 2008: 552). Further studies, based on smaller samples, have shown differences between the language practices of groups within a single bilingual school (e.g. Musk 2006, 2010).

This article compares attitudes towards Welsh, self-reported use of the language, and self-rated ability between Welsh-English bilingual school pupils. Participants were in post-compulsory education (Sixth Form) at the time of data collection and resided in two areas of Wales which differ linguistically. It draws upon quantitative questionnaire data and meta-linguistic narratives in order to examine the extent to which home language and dominance of Welsh in an area correlate with these aspects of bilingual identity. The article contributes to previous studies of Welsh usage by comparing a school where $80 \%$ of pupils come from Welsh-speaking homes with a school where $90 \%$ of pupils come from English-speaking homes. This raises the following questions:

1. Do speakers' attitudes towards Welsh and their self-rated ability influence their use of the language outside of the classroom?

2. Are attitudes more positive, and ability and use higher, in an area where Welsh is a dominant language?

3. To what extent are there differences in attitudes, ability and use between those from Welsh-speaking homes and English-speaking homes?

\subsection{The Welsh language}

Welsh (Cymraeg) is a Brythonic Celtic language spoken primarily in Wales (Cymru), one of the four countries of the United Kingdom (Office for National Statistics 2012). According to the last (2011) census, the language is spoken by approximately $19 \%$ of the population (562,000 speakers; Statistics for Wales 2012). Welsh is therefore a minority language in Wales and all speakers (with the exception of very young children) are bilingual with English. Welsh-medium education acts as both native language education for first language speakers and immersion education for children from English-speaking homes. The popularity of Welsh-medium education in predominantly English-speaking eastern areas, coupled with demo- 
graphic changes in the Welsh-speaking heartlands (in particular ongoing outward migration amongst those aged 16-24 and inward migration from English; see Statistics for Wales [2012]), has led to a situation whereby the majority of Welsh speakers now come from English-speaking homes and/or live outside the four counties where Welsh is more widely spoken (Anglesey, Gwynedd, Ceredigion and Carmarthenshire; Jones [2012: 6]). In certain eastern areas, a decline in local dialect features has been noted as "new speakers" acquire an intermediate variety between Standard Welsh and local dialect (cf. Jones 1998). Recent studies have also shown differences in the acquisition of grammatical gender (Thomas and Gathercole 2005), vocabulary (Gathercole and Thomas 2009), and knowledge of traditional plural suffixes (Thomas et al. 2012) amongst those who speak English at home and/or live in English-dominant areas.

\subsection{Language attitudes and use of Welsh}

Previous studies have indicated that there is overall support for bilingualism amongst the Welsh population. This is exemplified by both opinion polls (e.g. NOP 1995) and the increasing numbers of children from English monolingual homes attending Welsh-medium schools. Most recently, Hodges (2012) examined the reasons why 400 monolingual English-speaking parents in the Rhymni Valley in South Wales sent their children to Welsh-medium schools. She found that the most oft-cited reason was not for any perceived educational or economic benefits, but rather because of the cultural value of the language (Hodges 2012: 361).

Jones (2008) examines census and governmental data and performs regression analyses to show the extent to which independent variables are associated with the daily use of Welsh (Jones 2008: 552). Though the data comes from all age groups, there are important conclusions for the present study. (Jones 2008: 552-554) reports that being in the 16-29 age group reduces the likelihood of speaking Welsh on a daily basis by around two thirds $(\operatorname{Exp}[\mathrm{B}]=0.383) .{ }^{1}$ Furthermore, speakers who live in communities where over $30 \%$ of the population speak the language are twice as likely to use Welsh daily than those living in areas, such as $\mathrm{NE}$, where less than $30 \%$ speak the language $(\operatorname{Exp}[\mathrm{B}]=1.835)$. In areas where over $60 \%$ of the population speak Welsh the likelihood increases to four times $(\operatorname{Exp}[\mathrm{B}]=3.603)$. Using Welsh at home with both parents increased the likelihood

$1 \operatorname{Exp}(B)$ is the exponentiation of the B coefficient, which is an odds ratio, used by Jones (2008). 
of speaking Welsh daily by around two and a half times $(\operatorname{Exp}[\mathrm{B}]=2.435)$. This research indicates that Welsh is more likely to be used on a daily basis amongst young people when there are high numbers of Welsh-speaking families in an area. In areas where Welsh is not dominant, however, it appears that Welsh is not used to any great extent outside of school amongst many of those young people who come from English-speaking homes.

Morris (2007: 452-456) examined language use amongst in 12 towns in central and western areas of Wales and found that language use after compulsory education remained high only in heartland areas. Musk (2006) uses a conversation analytic (CA) framework in order to look at attitudes towards bilingualism amongst school children. His work with a bilingual school in an area where Welsh is the dominant community language leads him to distinguish between three categories: "Welsh-dominant bilinguals", "floaters" and "English-dominant bilinguals”. The attributes of these groups, after Musk (2006: 399-410), are summarised in Table 1.

The results of Musk's (2006) analysis mark a shift from home language as a factor which might influence acquisition to a social factor which may influence

Table 1: Attributes of social groups in a bilingual school (after Musk 2006: 399-410)

\begin{tabular}{|c|c|c|}
\hline Group & Main attributes & $\begin{array}{l}\text { Links with discourse surrounding } \\
\text { language matters }\end{array}$ \\
\hline $\begin{array}{l}\text { Welsh-dominant } \\
\text { bilinguals }\end{array}$ & $\begin{array}{l}\text { Speak Welsh at home. } \\
\text { May be more confident speaking } \\
\text { Welsh } \\
\text { Speak Welsh to other members of } \\
\text { the group and floaters but usually } \\
\text { speak English with English-dominant } \\
\text { bilinguals. }\end{array}$ & $\begin{array}{l}\text { Likely to condemn pupils who } \\
\text { refuse to speak Welsh. } \\
\text { Approve of the school's attitude } \\
\text { to Welshness. } \\
\text { Tend to show a commitment to } \\
\text { maintaining Welsh. }\end{array}$ \\
\hline Floaters & $\begin{array}{l}\text { Speak Welsh, English or both at } \\
\text { home. } \\
\text { Less likely to have a lack of } \\
\text { confidence in either language. } \\
\text { Most likely to accommodate to the } \\
\text { dominant language of the other } \\
\text { groups. }\end{array}$ & $\begin{array}{l}\text { May condemn those who refuse } \\
\text { to speak Welsh. } \\
\text { Tend to criticise some teachers' } \\
\text { methods of enforcing } \\
\text { bilingualism. } \\
\text { Tend to show a commitment to } \\
\text { maintaining Welsh. }\end{array}$ \\
\hline $\begin{array}{l}\text { English- } \\
\text { dominant } \\
\text { bilinguals }\end{array}$ & $\begin{array}{l}\text { Speak English at home. } \\
\text { Tend to lack confidence in Welsh. } \\
\text { Prefer to speak English with all other } \\
\text { groups. } \\
\text { Less likely to use Welsh after school. }\end{array}$ & $\begin{array}{l}\text { Tend to criticise any attempts to } \\
\text { curb their use of English. }\end{array}$ \\
\hline
\end{tabular}


all sorts of behavioural patterns, including language variation. Some interesting patterns emerge from this, the most important being that home language is a defining characteristic for the two "dominant" groups but also that there are some from English-speaking backgrounds who are committed to using Welsh. A further point of interest is that the distinguishing feature of the floaters from the English-dominant group is that floaters are less likely to lack confidence in their Welsh. This distinction is based on an area with a more equal proportion of pupils from Welsh-speaking and English-speaking backgrounds. It remains to be seen whether these groups exist in schools where 90\% of the students come from English-speaking homes and where attitudes towards the Welsh language may not be as positive as in Welsh-dominant areas.

\section{Methodology}

\subsection{North Wales}

North Wales (population, 623,744; Welsh Assembly Government [2005]) comprises the counties of Gwynedd, Isle of Anglesey (Ynys Môn) and Conwy in the North West, and Denbighshire (Sir Ddinbych), Flintshire (Sir Y Fflint) and Wrexham County Borough (Bwrdeistref Sirol Wrecsam) in the North East. The area under discussion is shown in Figure 1.

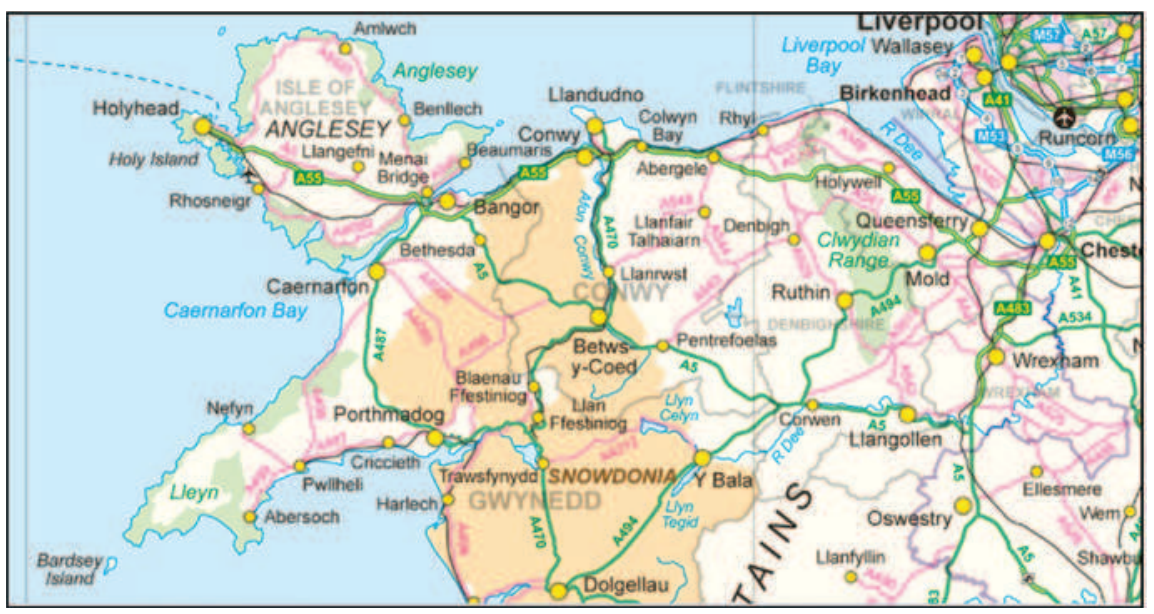

Fig. 1: North Wales. Contains Ordnance Survey Data $@$ Crown copyright and database copyright 2012 (created from 1: 1,000,000 scale digital data) 
The two locations in the study will be referred to as NW (North West) and NE (North East). Both locations are market towns and are comparable in many ways, especially in terms of population, yet crucially differ linguistically. NW is situated to the west of the county of Gwynedd. The town and immediate surrounding area has a population of 11,389 and 77.6\% are Welsh-speaking (Aitchison and Carter 2004). The population of NE is 11,998 , though in contrast to NW only $19.6 \%$ of the population speak Welsh (Aitchison and Carter 2004). The towns differ in their socio-economic status, and NW is generally more economically deprived than NE (Welsh Assembly Government 2011).

\subsection{Data collection}

Data were obtained from two cohorts of students in the Sixth Form units of state (comprehensive) schools in NW and NE. Due to the differing policies of Local Education Authorities, the schools differ slightly in terms of their policies towards both languages. The school in NW is a designated bilingual school where all subjects (with the exception of Welsh and English) are taught using both languages (Welsh Assembly Government 2007: 12). The school in NE is a Welsh-medium school. This is defined as a school in which "all subjects ... apart from English are taught through the medium of Welsh to all pupils, although some schools may introduce English terminology in one or two subjects" (Welsh Assembly Government 2007: 12). Students who were available at the time of data collection took place were selected and the sample in both areas was further stratified by their sex and home language (Welsh or English). All students came from similar backgrounds insofar as their parents had grown up in the area, had completed some form of post-compulsory education and most now held semiprofessional or professional occupations. The composition of the dataset is shown in Table 2.

Table 2: The sample of the current study

\begin{tabular}{lllllll}
\hline & \multicolumn{2}{c}{ NW } & & \multicolumn{2}{c}{ NE } & Total \\
\cline { 2 - 3 } & Male & Female & & Male & Female & \\
\hline Welsh at home & 3 & 2 & & 4 & 4 & 13 \\
English at home & 3 & 3 & 4 & 4 & 14 \\
Total & 6 & 5 & 8 & 8 & 27 \\
\hline
\end{tabular}


The qualitative data used in this article come from sociolinguistic interviews held with participants. These were conducted by the author, a native of North Wales and Welsh-English bilingual, as part of a wider study examining sociophonetic variation in bilingual speech (Morris 2013). Two separate interviews (in each language) were held with participants on separate days. Following the last interview, participants were asked to complete a written questionnaire, the results of which are the main focus of the current article.

\subsection{The questionnaire}

The aims of the questionnaire were to collect data on the demographic background of the participants and their language use and examine their attitudes. The data analysed here are largely based on how participants responded on a seven-point Likert scale to a number of statements which belonged to a similar "theme". Participants were asked to state how much they agreed or disagreed with a statement by selecting a number on the Likert scale, with the first point showing strong disagreement and the last point showing strong agreement.

The data on language use and language ability are based on self-reports from participants. The reliability of the data may be questionable, especially as speakers' assessments of their own ability were not measured objectively. Schmid (1981: 23) notes that "self-report data from an area that is as emotionally charged as linguistic proficiency might well be influenced more by how a person wishes to view herself than by an accurate assessment of her linguistic behavior". Although this is undoubtedly the case, the aim of the questions on ability in Welsh was to elicit data about how the participants feel about their ability and how this is correlates with other aspects of their bilingual identity.

There were two reasons why a language test was not administered. Firstly, such a language test was avoided in this study, as it would have required more time than was possible. Secondly, it would have stood in direct conflict with the aims of the sociolinguistic interview which was to relax the participants and divert their attention from language. In other words, a language test may have led to "examination stress" (Clyne 1995: 207) and the idea that they were being judged on their proficiency.

\subsection{Internal reliability and correlations}

Having calculated the scores from the Likert scales in each theme, the reliability of the statements within each theme was tested using Cronbach's Alpha. Each 
22. The following statements are about the work which is being done to promote Welsh. Say how much you agree or disagree with each one ( 1 = strongly disagree, 7 = strongly agree):

Private companies should do more to offer a bilingual service.

\begin{tabular}{ccccccc} 
Strongly disagree & & & & \multicolumn{3}{c}{ Strongly agree } \\
1 & 2 & 3 & 4 & 5 & 6 & 7
\end{tabular}

More jobs should be filled by Welsh-speakers only, in order to offer a bilingual service.

\begin{tabular}{cccccccc}
\multicolumn{2}{c}{ Strongly disagree } & & & & & Strongly agree \\
1 & 2 & 3 & 4 & 5 & 6 & 7
\end{tabular}

Councils should do something to ensure that people who don't speak Welsh do not move into areas where the language is strong.

$\begin{array}{ccccccc}\text { Strongly disagree } & & & & & \text { Strongly agree } \\ 1 & 2 & 3 & 4 & 5 & 6 & 7\end{array}$

The National Assembly concentrates too much on the language.

$\begin{array}{ccccccc}\text { Strongly disagree } & & & & & \text { Strongly agree } \\ 1 & 2 & 3 & 4 & 5 & 6 & 7\end{array}$

Councils across Wales should create more Welsh-medium schools.

\begin{tabular}{ccccccc}
\multicolumn{2}{c}{ Strongly disagree } & & & & Strongly agree \\
1 & 2 & 3 & 4 & 5 & 6 & 7
\end{tabular}

Fig. 2: Example of statements used to elicit attitudinal data

theme consisted of either four or five statements. For example, participants were asked to state to what extent they agreed with five statements about the promotion of Welsh, as shown in Figure 2.

Cronbach's Alpha gives coefficients which are "measures of internal consistency or equivalence” (Zeller and Carmines 1980: 56-59, italics removed). In other words, it is a measurement which ensures that all items within a theme are reliable indicators of what is under investigation. The mean Likert scores for each statement within a group are compared, and groups which contain similar Likert scores receive a higher coefficient and are deemed to be more reliable. Questions which aimed to elicit participants' opinions of English failed to reach the threshold for reliability in the social sciences (Dörnyei 2003: 112). Table 3 shows the Cronbach's Alpha for each theme. 
Table 3: Cronbach's Alpha results

\begin{tabular}{ll}
\hline Factor & Cronbach's Alpha \\
\hline Welsh in the area (WIA) & 0.850 \\
Promotion of Welsh (PROM) & 0.657 \\
Opinion of Welsh (OW) & 0.834 \\
Opinion of English (OE) & 0.541 \\
Self-reported ability in Welsh (ABIL) & 0.906 \\
Use of Welsh & 0.809 \\
\hline
\end{tabular}

In order to avoid multicollinearity, the correlation between the different themes of the questionnaire was calculated using Pearson's product moment correlation coefficient (Blaikie 2003: 108; see also Drummond 2010). Pearson's $r$ shows how variables correlate on a ratio scale (Baayen 2009: 87), and variables which have a significant correlation coefficient are not independent.

Pearson's $r$ is suitable for comparisons between the different modules of the questionnaires, but it is not a suitable measure for the relationship between ordinal scale and nominal data (Rasinger 2008: 149). In other words, it is not appropriate to use Pearson's $r$ in order to test whether the attitudinal data is linked to participants' area or home language.

The significance of the relationship between attitudes and the nominal independent variables is calculated here using the Mann-Whitney $U$ test (Rasinger 2008: 203). ${ }^{2}$ The Mann-Whitney $U$ test is the non-parametric equivalent to the unpaired t-test and does not assume a Gaussian distribution (Motulsky 1995: Chapter 37). The data is non-Gaussian nature as the mode, median and mean values for overall scores differ (meaning that the distribution is not bell-shaped). In addition, a non-parametric test is preferable as we are dealing with the scores of participants and their rank in relation to others (Motulsky 1995: Chapter 37). While it is possible to use the Mann-Whitney test on samples which are unequal in size, the larger sample should be twenty or fewer which is the case here (Robson 1994: 114). Linear regression would also be problematic as the scores do not represent a continuous scale (Drager and Hay 2012: 59).

2 Calculations were performed using the R Commander package (Fox 2005) in the R statistics environment (R Development Core Team 2011). 


\section{Results}

\subsection{Attitudes towards Welsh}

The participants' attitudes towards Welsh were gauged by three questions on the questionnaire. Question 23 asked participants whether they would want their own children to be educated primarily through the medium of Welsh, question 29 presented five items on a seven-point Likert scale about Welsh language planning, and question 30 presented three items on a seven-point Likert scale which asked the extent to which participants agreed that Welsh was useful, friendly and beautiful. On each Likert scale, a score of one indicated strong disagreement and seven indicated strong agreement.

\subsubsection{Welsh-medium education}

$96.3 \%$ of participants $(n=26)$ would choose to educate their children through the medium of Welsh. Those participants who spoke Welsh at home tended to give naturalistic reasons for sending their children to Welsh-medium schools. They stated that as Welsh is their first language, Welsh-medium education is the obvious choice for them. The participants from English-speaking homes gave symbolic or capitalistic reasons for wanting to send their children to Welsh-medium schools. Out of the 14 participants from English-speaking homes, nine stated that it was important to learn the national language, and a duty to pass it on to future generations. Five of the participants said that Welsh-English bilingualism was a useful skill to have in contemporary Wales.

\subsubsection{Language planning}

Participants were asked to rate the extent to which they agreed with the following statements:

1. Private companies should do more to offer a bilingual service.

2. More jobs should be filled by Welsh-speakers in order to offer a bilingual service.

3. Councils should ensure that those who do not speak Welsh do not move into villages where the language is strong.

4. The National Assembly concentrates too much on language (reversed item).

5. Councils should create more Welsh-medium schools. 


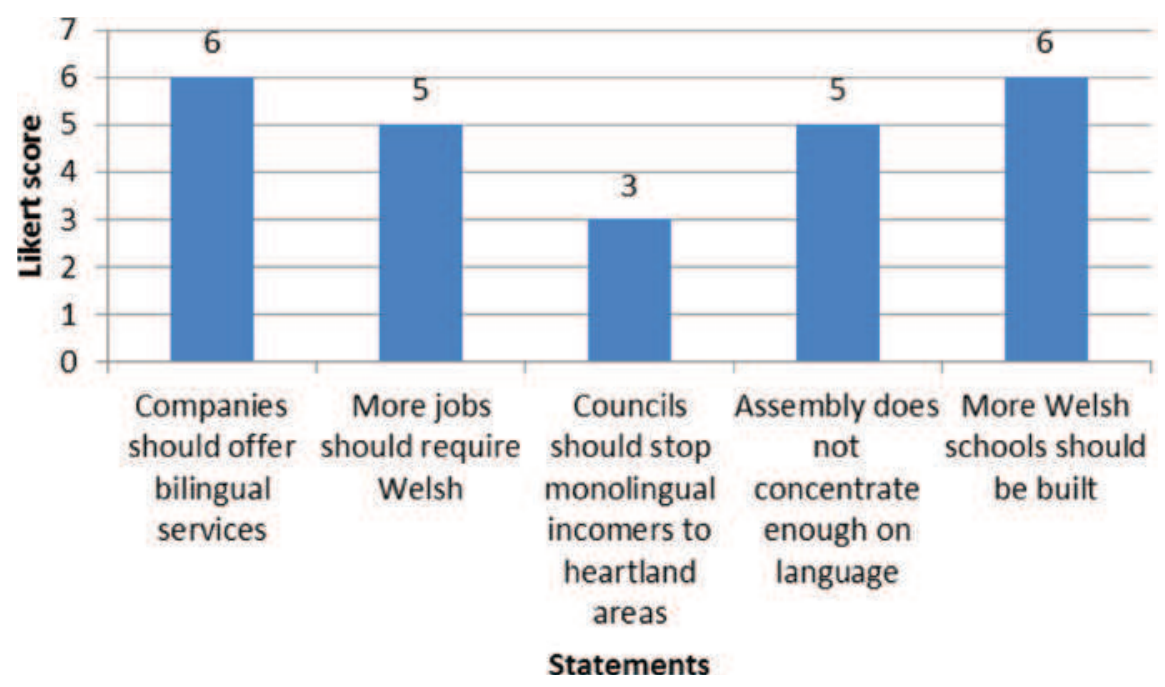

Fig. 3: Median Likert scores for statements on language planning ( $1=$ strongly disagree, $7=$ strongly agree)

Based on the overall median for statements 1-5 (above), there were no significant differences between the two areas $(U=55.5, p=0.1128)$, home language groups ( $U=93.5, p=0.9224)$, or sexes $(U=84, p=0.7514)$. Figure 3 shows the median responses for each item.

The median scores across the entire dataset show a tendency to agree that more bilingual services amongst companies and more Welsh-medium schools are needed. There is also agreement that the National Assembly should do more for the language and that more jobs should require the use of Welsh. Interestingly, participants disagree with the most controversial measure, which would be to regulate local housing in heartland areas. A number of participants in NW mentioned that the area had changed in their lifetimes due to an influx of English monolinguals from either other parts of Wales or Britain, but participants did not seem to view this as particularly negative. Carys, for example, mentioned the change in dynamic between her time in a local village primary school and secondary school with a wider catchment area:

Dod i fyny i ysgol [Uwchradd], ma' 'na lot o Saesneg o’i gymharu efo ysgol fach.... Mae lot o bobl o deuluoedd Saesneg

[Coming up to (secondary) school there's a lot of English compared with little school.... There's a lot of English families.]

Carys (NW Welsh) 
She continues, however, to state that Welsh is still necessary in the school:

'Swn i ddim yn licio bod yn yr ysgol taswn i ddim yn siarad Cymraeg achos Cymraeg dan ni'n siarad gyda'n gilydd

[I wouldn't like to be in the school if I didn't speak Welsh because it’s Welsh that we speak with each other.]

Carys (NW Welsh)

Graham (NW English) scored the second lowest for positive attitude towards language planning (12 out of 35), and was the only participant to mention language policies in the interview. He mentioned that:

When I'm working ... I get a lot of people coming to us saying we need to do more signs in Welsh. It's unnecessary.

Graham (NW English)

Graham also disagreed that Welsh is useful and strongly disagreed that Welsh is friendly and beautiful. He scored the lowest for this area (5 out of 35) and was the only participant to fall under the halfway score for opinion of Welsh. It is to opinions of the language that we now turn.

\subsubsection{Opinion of Welsh}

There were no significant differences between the different areas $(U=96$, $p=0.708)$, home language groups $(U=70.5, p=0.33)$ or sexes $(U=123, p=0.129)$ in relation to the opinions of Welsh (recall that speakers' opinion of English are not included in the analysis). Figure 4, below, shows the median Likert scores for individual items.

The scores for the "Welsh is beautiful" and "Welsh is friendly" statements indicate overall affection for the language on the part of the participants, regardless of their background. This could be seen as a success of language planning in the Welsh context, as Welsh is seen as a useful commodity to have despite all of its speakers being bilingual with English. This was not mentioned to any great extent in the interviews, though, and it remains to be seen whether the overall positive opinions of Welsh correlate with actual language use.

Participants are overwhelmingly in favour of Welsh-medium education and hold affectionate views towards the language. There was also overall support for companies to take more responsibility in providing services and for more Welsh-medium schools to be built. This suggests that Welsh is valued positively both as a skill, which will help advance the future careers of the participant, and as a cultural artifact, which is a symbol of their own Welsh identity. Though there is little in the qualitative data to substantiate this claim, it does, very broadly, 


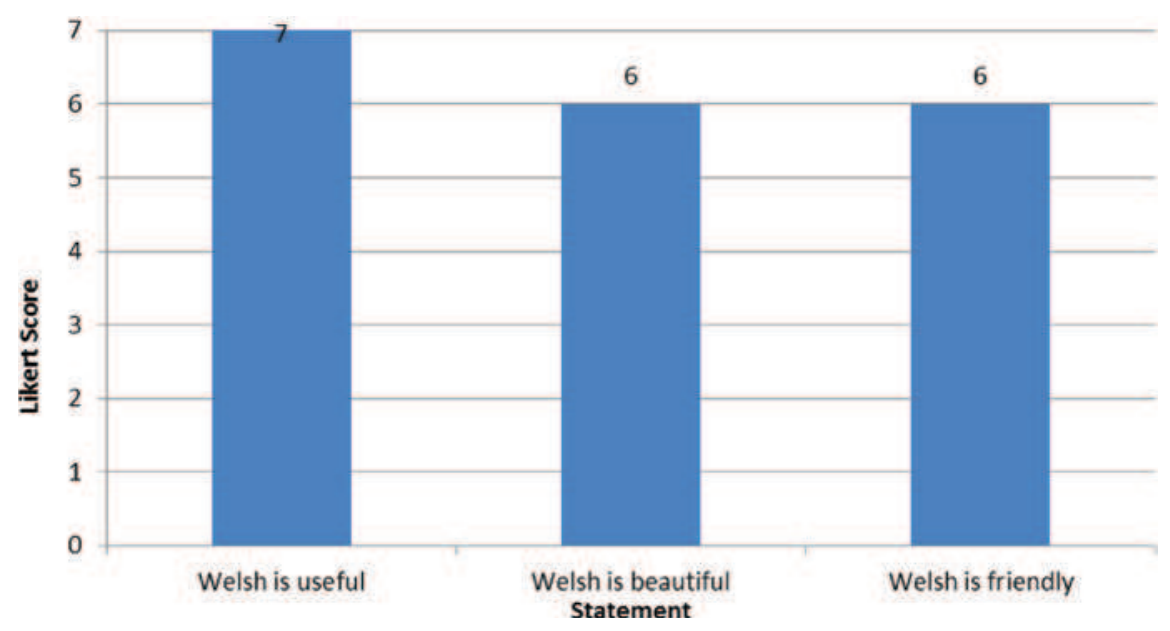

Fig. 4: Median Likert scores for statements on opinion of Welsh ( $1=$ strongly disagree, $7=$ strongly agree)

support the findings of previous research on opinions towards Welsh (e.g. Coupland et al. 2006) and Welsh-medium education (e.g. Hodges 2012).

Closer inspection of the results of the Pearson's $r$ shows a significantly strong correlation between self-reported ability and both promotion of Welsh $(r=0.368$, $p=0.006)$ and opinion of Welsh $(r=0.511, p=0.006)$. Figure 5 shows the correlation between the total scores for both promotion of Welsh and opinion of Welsh (OPIN), and self-reported ability (ABIL).

For the combined attitudinal score, there is a moderate correlation between self-reported ability and attitudes towards Welsh $(r=0.473, p=0.013)$. This suggests a tendency for those who feel less confident in their ability in Welsh to be less likely to hold very positive attitudes towards the language. The interview data from both Jen (NW English) and Graham (NW English) suggest that both speakers feel separate to Welsh-speakers in their own peer group. From the beginning of the interview, Jen states that:

I think I can't [speak Welsh] though 'cause I remember the school was quite bitchy 'cause I was in primary school they used to start on me for it a lot for not being able to say it properly. 'Cause I was like one of the better performing kids in my year for everything apart from reading Welsh ... and that was really embarrassing and I think that's why I don't like it.... I got good [grades] in the GCSEs, like I got Bs and stuff but I just don't like it. Jen (NW English)

Graham appears to share a similar attitude to Jen and sets himself apart from those for whom Welsh is the preferred language. 


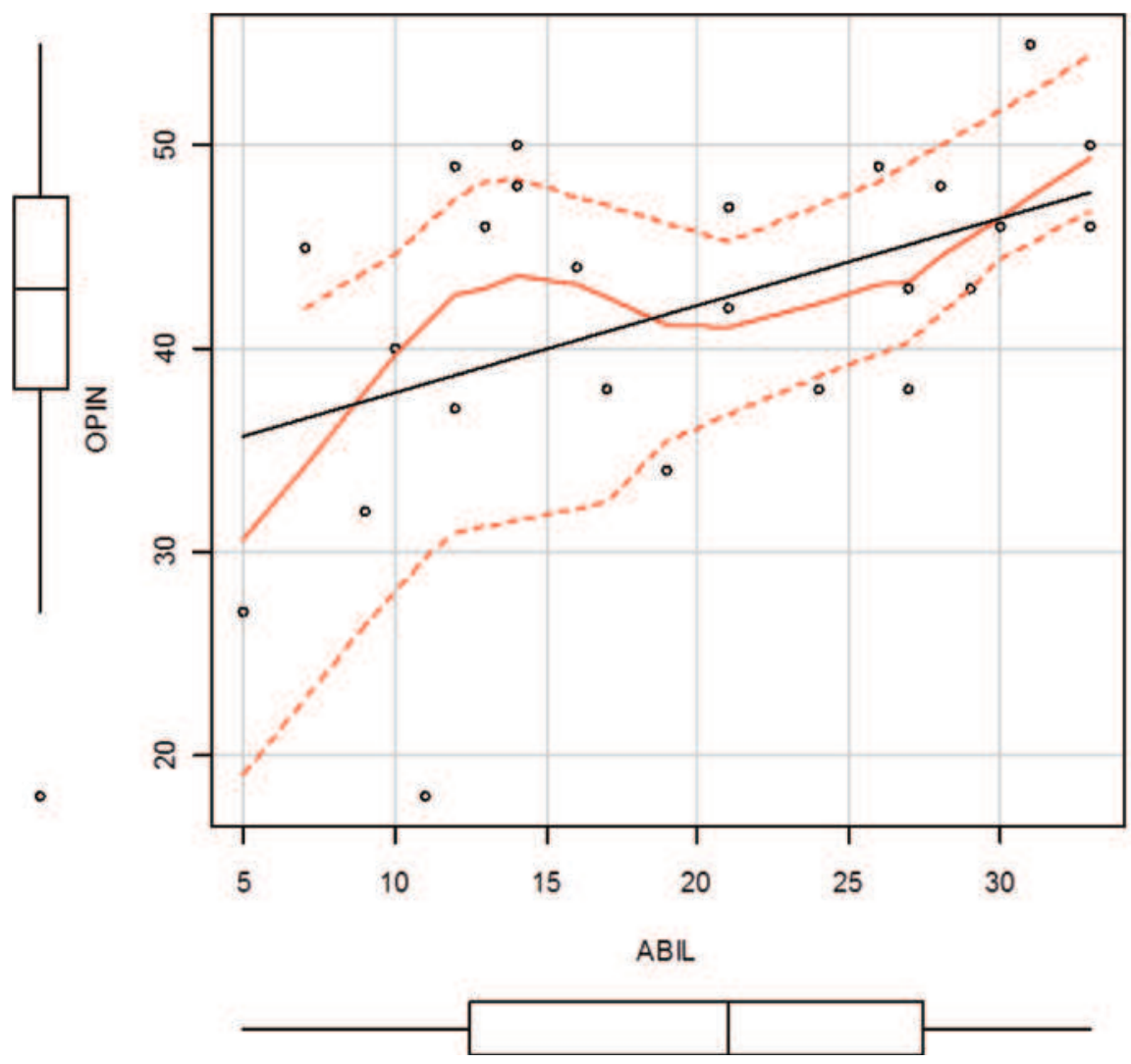

Fig. 5: Correlation between opinions of Welsh and self-rated ability

They're really protective of their language.... Sometimes I get really ridiculed for speaking English.... No one else can see it but me because it's happening to me.

Graham (NW English)

In light of the above extracts, it is perhaps unsurprising that both Jen and Graham have some of the lowest scores for the different themes of the questionnaire data.

\subsection{Self-reported ability}

Question 31 aimed to discover whether students felt that they made few mistakes in Welsh and do not need to improve their language skills, and whether students 


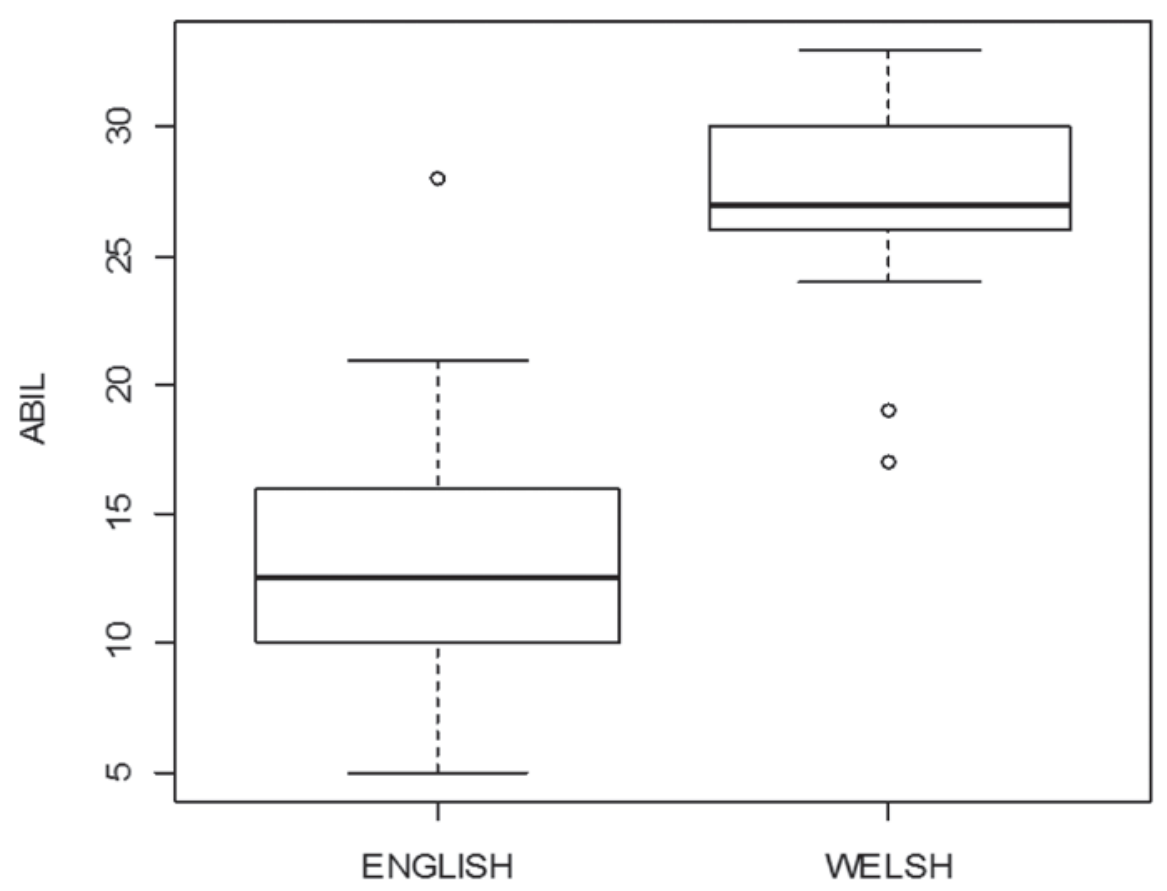

$\mathrm{HL}$

Fig. 6: Participant ratings for self-reported ability by home language

felt they spoke, read and wrote in Welsh better than they do in English. Overall, there was no significant correlation between the ability and speaker sex $(U=114$, $p=0.274)$ or area $(U=99, p=0.604)$. There was a strong link between home language and self-reported ability with those from Welsh-speaking homes being more likely to rate their own ability as higher $(U=11, p=<0.005)$. Figure 6 shows participants from the two home language groups differed in their scores for ability.

The median scores above indicate that those who speak Welsh as a home language and who are educated primarily or solely in Welsh strongly rate their abilities in speaking, reading and writing. This confidence in their own abilities does not depend on the level of Welsh in their area. This group also largely agreed that they made few mistakes in Welsh and were ambivalent about the need to improve their Welsh. This is unsurprising as talking about making mistakes or improving language skills is perhaps more appropriate when discussing a second or foreign language rather than one's native tongue. 
The results for those who speak English at home indicate that overall this group disagree quite strongly that they speak, write, or read Welsh better than English. This again is unsurprising to a certain extent as English is their first language, though one might hope that as a result of immersion education they would score an average of four across at least the first three items (which would imply that they neither agree nor disagree that either language is better). Though this group agreed quite strongly that they made mistakes in Welsh, they tended to neither agree nor disagree that they needed to improve the level of their language. So far we have seen that there is a moderate positive correlation between participants' opinions of Welsh and how they rate their ability in their language. The remainder of this article will be spent examining the data on participants' language use in order to find out whether there are direct correlations between use, opinion and ability.

\subsection{Language use}

Question 26 asked participants to specify the language they used most often when talking with friends, phoning helplines and completing official forms. Question 27 asked them to specify how often they accessed certain media or attended cultural events in both languages. Answers were scored in order to catalogue language use quantitatively, as shown in Table 4.

Despite the use of Welsh being higher in NW than in NE, the provenance of our individual speakers does not have a significant effect on their use of Welsh $(U=121, p=0.1062)$. Speaker sex also plays no significant role in the use of Welsh ( $U=93.5, p=0.9221)$. The participants' home language was highly significant, however, which means that those who speak Welsh at home are more likely to use Welsh outside of the home and access services and media in Welsh $(U=13$, $p=<0.00$ ). Figure 7, below, shows the range of scores by home language.

Table 4: Scoring for language use

\begin{tabular}{ll}
\hline Score & Majority Language \\
\hline 0 & English is the main language. \\
& English-medium media/cultural events are accessed more frequently than \\
& Welsh equivalents. \\
& Both languages used equally. \\
2 & Welsh is the main language. \\
& Welsh-medium media accessed more frequently than English equivalents. \\
\hline
\end{tabular}




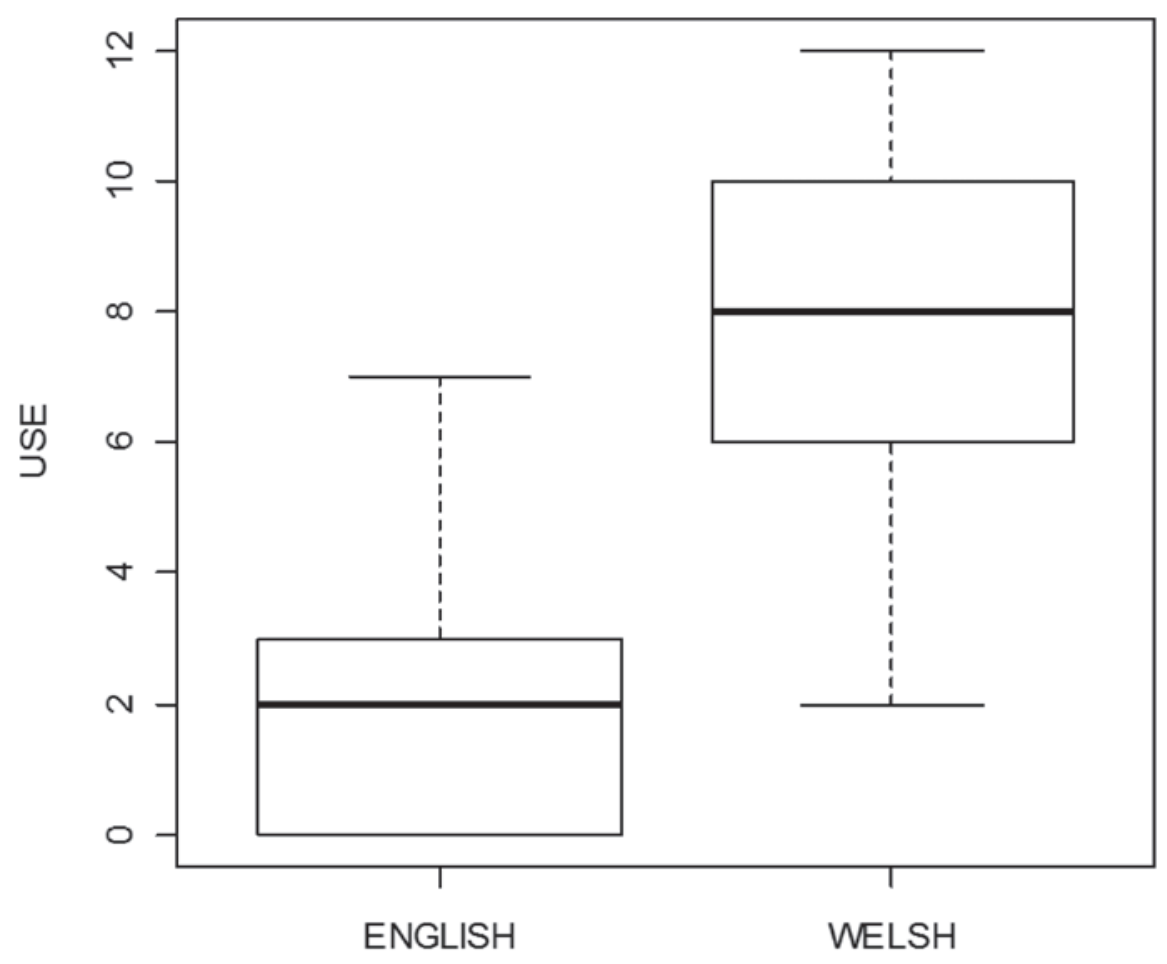

Home_Lang

Fig. 7: Participant scores for language use by home language

78.6\% of participants from English-speaking homes scored between 0 and 3 for their use of Welsh $(n=11)$. These participants all spoke English with their peers and access English media more frequently than Welsh media. The remaining three participants in this group come from NW, speak both Welsh and English in the peer group, and access some media in Welsh as frequently as their equivalent in English. The use of Welsh amongst those who speak English at home is, on the whole, very low. There was not a significant difference between NE and NW in the English at home group $(U=37.5, p=0.08392)$.

We have already seen that two participants from NW do not like to speak Welsh (Jen and Graham) and it appears that in NW there are friendship groups based on language. Siân made reference to this, stating that:

Mae gynnych chi'r criw Cymraeg a'r criw Saesneg ... a'r half and half 'de, hanner Cymraeg, hanner Saesneg. ... Iaith oedd y clics mwy "na dim byd 
[You've got the Welsh crew and the English crew ... and the half and half like, half Welsh half English.... Language is the clicks more than anything.]

Siân (NW Welsh)

This corresponds to Musk's (2006) distinction between "Welsh-dominant", "English-dominant" and "floaters". Another possibility is that some students are being non-convergent in their modes of talk and speaking their own preferred languages. Gafaranga and Torras Calvo (2001: 212) differentiate between normative and non-normative conduct in bilingual contexts. He presents examples which show two separate cases of bilingual modes of talk. In the first example speakers become aware that their talk is divergent (that they are speaking in different languages) and one speaker accommodates to the other speaker's language. This shows that for the interlocutors non-convergence is non-normative behaviour. In another example, however, the fact that speakers continue to speak different languages in conversation leads Gafaranga and Torras Calvo (2001: 212) to conclude that this is normative conduct for the speakers. In NW, this certainly seemed to be the case for many interactions and there were many instances where conversations between participants and teachers could be counted as nonconvergent modes of talk. In NE, this behaviour does not seem as widespread (especially with teachers as this would not be tolerated in Welsh-medium education in the North East) though Glenys (NE Welsh) mentioned that there is one student in her cohort who refuses to speak English to her peers.

Figure 7 shows that the range of use of Welsh for those participants from Welsh-speaking homes is larger than those from English-speaking homes. There was a significant difference between those from Welsh-speaking homes who live in NW and those who live in NE with regards to language use $(U=34, p=0.046)$. Glenys explained her own switch from Welsh to English with the peer group came when she arrived at Secondary school:

On i'n siarad Cymraeg gyda ffrindie fi [o'r ysgol Gynradd] a wedyn dw i'n cofio oedd 'na rywun yn galw fi['n] swot yn siarad Cymraeg ac on i'n teimlo rili upset.... Dw i dal efo ffrind gore $f$ ... yn siarad Cymraeg ond Saesneg dan ni'n siarad [gyda phobl eraill] rili.

[I used to speak Welsh with my friends (from primary school) and then I remember there was someone who used to call me swot for speaking Welsh and I felt really upset.... I still speak Welsh with my best friend but it's English that we speak (with other people) really].

Glenys (NE Welsh)

Glenys scored 43 out of 56 for her opinion of Welsh and 27 out of 35 for her ability in the language. She also comes from a family who is highly involved in the Welsh-speaking community of the area and speaks Welsh with her two best 
friends, one of whom is from an English-speaking home (Sarah). The data from her interview, such as the statement above, indicate that she is aware of fitting in with her peers and even claims that she does not want to get picked on for using Welsh with the peer group. She strikes a balance between the Welsh language and her family, and the dynamics of her peer group when she says that:

\footnotetext{
I don't speak Welsh with, like, loads of people from school, but if friends come to my house everybody knows to speak Welsh because like my Mum would go absolutely crazy.... I've decided that it's kind of better not to get bullied and speak English.... You don't get bullied actually but ... erm . . . yeah. ... When I have children I want to speak Welsh to them and go to a Welsh-speaking school and stuff.

Glenys (NE Welsh)
}

Looking at the dataset as a whole there is a highly significant correlation between use of Welsh and self-reported ability $(r=0.620, p<0.001)$. Figure 8 shows this correlation across the entire dataset.

Closer inspection of Figure 8 reveals a highly significant correlation and language use increases amongst those who have more confidence in their Welshlanguage abilities. We have dealt with Glenys, above, and in light of the qualitative evidence it is not surprising that her self-rated ability is high but her language use is relatively low. Andy (NW English) has low self-rated ability but relatively high use. This score comes from him listening to Welsh-language radio and attending Welsh-language theatre productions as frequently as he does in English (daily and monthly respectively). Perhaps most importantly, Andy and Lizzie are the only two participants from English-speaking homes to belong to friendship groups where they are the only people from English-speaking homes. Nicola (NE English) also has a high self-rated ability compared to her actual language use score. Though her score was low, she does listen to the radio and read books in Welsh every few weeks, which was more frequently than she does in English. She also agreed that her written Welsh was better than her English (scoring 5 out of 7) which contributed to her high score in self-rated ability.

\section{Discussion}

The participants' opinions of Welsh were mostly positive, with no significant differences between the home language and area groups. The general consensus is that more should be done to promote bilingualism in Wales and that the Welsh language is beautiful, friendly and, perhaps most importantly, useful for their future job prospects. Questionnaire data of this nature should always be treated cautiously, but this result does suggest that the acquisition of Welsh is seen 

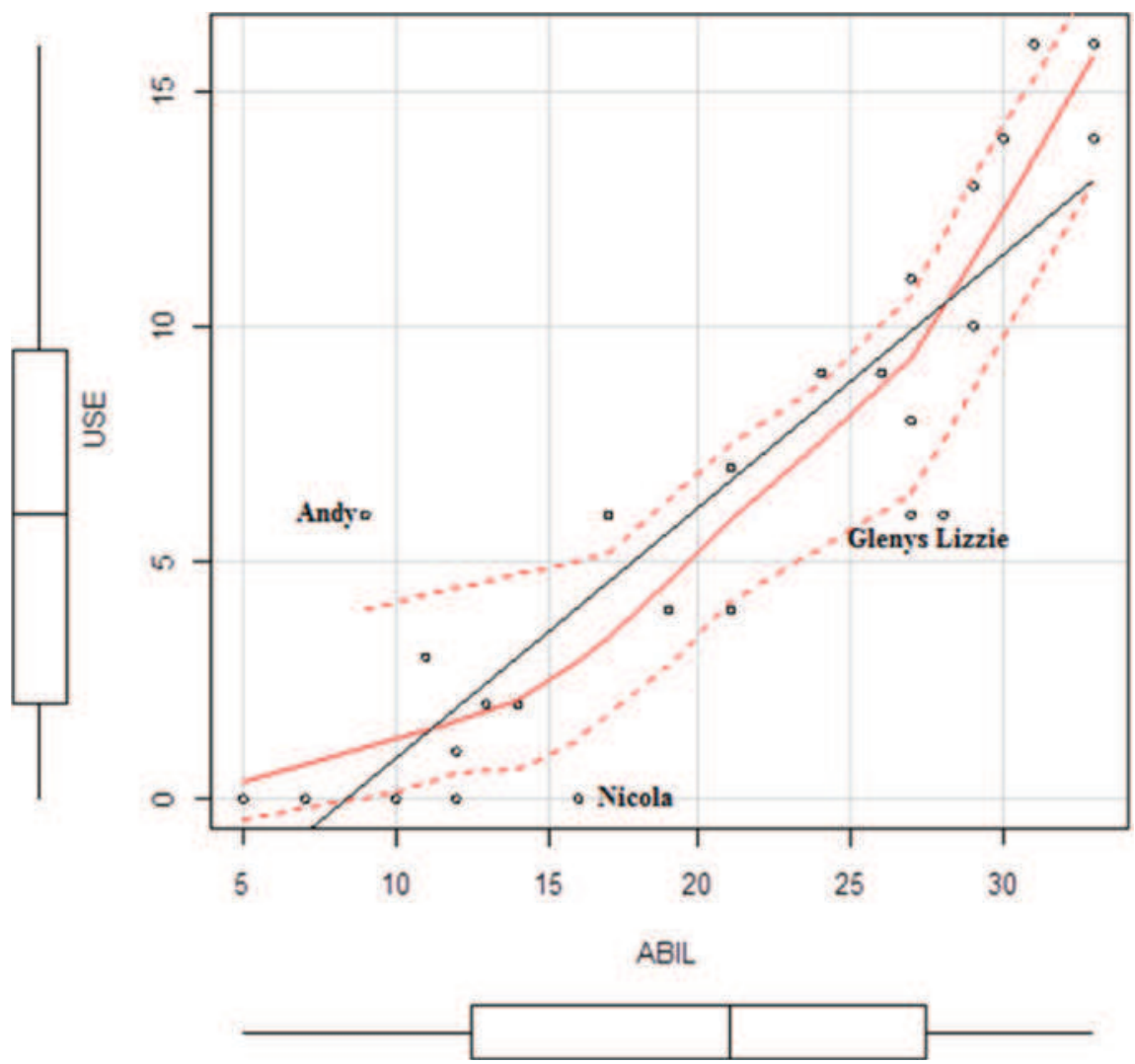

Fig. 8: Correlation between self-reported ability and language use

as being beneficial by students, as has been shown to be the case for parents (cf. Hodges 2012), even if this belief does not necessarily stimulate use of the language.

Despite overall positive attitudes, however, the data examined in this article have shown that positive opinions towards Welsh are moderately correlated with how a speaker rates her ability. In the case of individuals, notably those from English-speaking homes in NW, particularly negative opinions appear to be accompanied by negative experiences or comments on speakers' Welsh ability by others. This has hitherto been unexplored in studies of Welsh usage and more case studies of individual students could be of interest to the Welsh Assembly Government, who aim to encourage the use of Welsh amongst young people (Welsh Assembly Government 2003: 48). 
A more complicated situation arises from the data on language use. Those from English-speaking homes tend to use Welsh less than those who speak Welsh at home. This supports previous studies of Welsh usage (e.g. Jones 2008), but no difference was found between the English home-language groups in each area. This contradicts recent research which claims that those from English-speaking homes in predominantly Welsh-speaking areas assimilate linguistically (Estyn 2013) and suggests that this group minimise their use of Welsh inside and outside of school where possible. This is reflected in the peer-group dynamics in NW. Those who come from English-language homes in NW tend to form peer groups which exclusively use English. There were, of course, exceptions (Lizzie and Andy) who did become normalised into Welsh-speaking peer groups (cf. Musk's [2006] floaters), but on the whole there appears to be little orientation towards Welsh amongst those from monolingual English backgrounds in the sample.

Those from Welsh-speaking homes tend to rate their ability in Welsh as higher than those from English-speaking homes. It is not surprising that those from English-speaking homes rate their abilities in Welsh as lower than in their first language, but it was particularly noteworthy that they did not tend to view their command of Welsh as equal with English and that the dominant language of the school, and indeed of the wider community, had no visible effect on creating more confident L2 speakers. As for other groups, confidence in Welsh is linked with use of the language. It appears that those from English-speaking homes who live in Welsh-dominant areas are able to choose to live their lives through English and minimise their use of Welsh, which in turn affects their confidence.

More ethnographically-oriented research might uncover the reasons for this, though I would argue that the lower scores for self-rated ability amongst those from English-language homes in this area suggests an issue with confidence in Welsh which may affect engagement with Welsh and, in Welsh-dominant areas, impede linguistic assimilation.

Unlike those from English-language homes, a distinction can be made between Welsh home-language speakers in NW and NE, as those in NE tend to engage less frequently with the Welsh language. Again, a symptom of this can be found in the structure of social networks in NE. Here, there are no languagespecific peer groups as communication is largely through English. The use of Welsh with peers appears to be stigmatised in NE, which means that those from Welsh-speaking homes are using the language less than those from NW in situations outside of the home. There were, however, hints that communication between individuals belonging to the NE Welsh group would be through Welsh and examples of "brave" individuals who engaged in non-convergent modes of talk were given. 
Finally, it is perhaps not surprising that speaker sex did not correlate with any of the questionnaire data. None of the previous accounts of Welsh acquisition or use have found sex to be a significant indicator. Furthermore, the societal roles ascribed to males and females are perhaps less pronounced in North Wales than in many other regional minority language bilingual situations, where language proficiency and use has differed between males and females due to differences in social position (e.g. Gal 1978).

\section{Conclusion}

This article has examined young people's engagement with Welsh in North Wales. It has taken a different approach than previous studies insofar as it has concentrated on a fewer number of speakers in order to examine quantitative and qualitative data, and has also considered the interplay between opinions, speaker confidence in Welsh ability, and use of Welsh outside of the classroom with area and home language.

Welsh is viewed positively by most participants regardless of their linguistic background. The language is seen as both a positive emblem of Welsh national identity and also a useful skill for future employment in contemporary Wales. While the overall trend was to support for the language, however, there were a few participants who harboured particularly negative views. Such participants tended to come from English-speaking homes in NW (where they are in a minority) and have little confidence in their language skills. They also alluded to (in their own view) receiving negative comments from their teachers or peers about their Welsh.

Despite generally positive attitudes, the data shows that high use of Welsh is restricted to those from Welsh-speaking homes in NW. There was a significant difference between this group and those from Welsh-speaking homes in NE, which appears to be due to the fact that the broad social networks in NE are all English-speaking. In light of this, it is not surprising that social lives and activities are played out in English, with Welsh being reserved for some small-group interactions amongst those from Welsh-speaking homes.

In NW, participants tended to belong to a peer group based on their home language, whereas in NE, English was the language of all peer groups. For this reason, there were no significant differences between the English home-language groups in both areas in terms of usage. It is perhaps surprising that those from English-speaking homes do not tend to assimilate linguistically with the Welshspeaking majority and further work is needed to examine the extent to which this group can avoid active production of Welsh in their everyday lives. 
A number of factors, such as the sheer dominance of English in youth culture, may explain why the use of Welsh by those from English-speaking homes is low regardless of local dynamics. It is clear from this study, however, that low use is highly correlated with low self-rated ability. Pupils who come from Englishlanguage homes tend to lack confidence in their ability to speak Welsh compared to English, despite over ten years of immersion education. I would argue that the issue of speaker confidence has been largely ignored in previous studies, with lack of Welsh use being attributed to the dominance or prestige of English in the wider community and in youth culture or to negative opinions of the language amongst certain groups of young people. More ethnographic work in this area is required, so that we can examine the extent to which lack of confidence is a barrier to minority language engagement, and begin to enable young people to use Welsh beyond the classroom.

\section{References}

Aitchison, John \& Harold Carter. 2004. Spreading the word: The Welsh language 2001. Talybont: Y Lolfa.

Baayen, Harald. 2009. Analyzing linguistic data: A practical introduction to statistics. Cambridge: Cambridge University Press.

Blaikie, Norman W. H. 2003. Analyzing quantitative data. London: SAGE.

Clyne, Michael. 1995. [Review of] Werner Koller, Deutsche in der Deutschschweiz. Eine sprachsoziologische Untersuchung. Mit einem Beitrag von Heinrich Hänger. Aarau: Verlag Sauerländer, 1992, 382 pp. Multilingua 14. 205-207.

Coupland, Nicholad, Hywel Bishop, Betsy Evans \& Peter Garrett. 2006. Imagining Wales and the Welsh Language: Ethnolinguistic subjectivities and demographic flow. Journal of Language and Social Psychology 25. 351-376.

Dörnyei, Zoltán. 2003. Questionnaires in Second Language research: Construction, administration, and processing. Mahwah: Lawrence Erlbaum Associates.

Drager, Katie \& Jennifer Hay. 2012. Exploiting random intercepts: Two case studies in Sociophonetics. Language Variation and Change 24(1). 59-78.

Drummond, Rob. 2010. Sociolinguistic variation in a second language: The influence of local accent on the pronunciation of non-native English speakers living in Manchester. Manchester: University of Manchester dissertation.

Estyn. 2013. Welsh in the Foundation Phase: Developing Welsh as a first language in primary schools and the non-maintained sector. http://www.estyn.gov.uk/english/ docViewer/296123.1/welsh-in-the-foundation-phase-developing-welsh-as-a-firstlanguage-in-primary-schools-and-the-non-maintained-sector-december2013/?navmap=30,163, (accessed 5 December 2013).

Fox, John. 2005. The R Commander: A basic statistics graphical user interface to R. Journal of Statistical Software 14(9). 1-42.

Gafaranga, Joseph \& Maria Carme Torras Calvo. 2001. Language versus medium in the study of bilingual conversation. International Journal of Bilingualism 5(2). 195-219. 
Gal, Susan. 1978. Peasant men can't get wives: Language change and sex roles in a bilingual community. Language in Society 7.1-16.

Gathercole, Virginia C. Mueller \& Enlli Môn Thomas. 2009. Bilingual first-language development: Dominant language takeover, threatened minority language take-up. Bilingualism, Language and Cognition 12(2). 213-237.

Hodges, Rhian. 2012. Welsh-medium education and parental incentives - the case of the Rhymni Valley, Caerffili. International Journal of Bilingual Education and Bilingualism 15(3). 355-73.

Jones, Hywel M. 2008. The changing social context of Welsh: A review of statistical trends. International Journal of Bilingual Education and Bilingualism 11(5). 541-557

Jones, Hywel M. 2012. A statistical overview of the Welsh Language. http://www.poliglotti4.eu/docs/A_statistical_overview_of_the_Welsh_languagef2.pdf (accessed 15 May 2014).

Jones, Mari C. 1998. Language obsolescence and revitalization, linguistic change in two sociolinguistically contrasting Welsh communities. Oxford: Clarendon Press.

Morris, Delyth. 2007. Young people's social networks and language use: The case of Wales. Sociolinguistic Studies 1(3). 435-460.

Morris, Jonathan. 2013. Sociolinguistic variation and minority language bilingualism: An investigation of Welsh-English bilinguals in North Wales. Manchester: University of Manchester dissertation. https://www.escholar.manchester.ac.uk/api/ datastream?publicationPid=uk-ac-man-scw:205563\&datastreamld=FULL-TEXT.PDF (accessed May 2014).

Motulsky, Harvey. 1995. Intuitive biostatistics. Oxford: Oxford University Press.

Musk, Nigel. 2006. Performing bilingualism in Wales with the spotlight on Welsh. A study of the language practices of young people in bilingual education. Linköping: Linköping University dissertation. http://liu.diva-portal.org/smash/get/diva2:22924/FULLTEXT01. pdf (accessed May 2014).

Musk, Nigel. 2010. Bilingualisms-in-practice at the meso level: An example from a bilingual school in Wales. International Journal of the Sociology of Language 202: 41-62.

NOP. 1995. Public attitudes to the Welsh language. London: NOP Social \& Political.

Office for National Statistics. 2012. Administrative geography. http://www.ons.gov.uk/ons/ guide-method/geography/beginner-s-guide/administrative/index.html (accessed 10 October 2012).

Rasinger, Sebastian M. 2008. Quantitative research in linguistics: An introduction. London: Continuum.

R Development Core Team. 2011. R: A language and environment for statistical computing. R Foundation for Statistical Computing, Vienna: Austria. http://www.R-project.org/ (accessed 28 June 2012).

Robson, Colin. 1994. Experiment, design and statistics in Psychology, 3rd edn. London: Penguin.

Schmid, Carol L. 1981. Conflict and consensus in Switzerland. Berkeley, Los Angeles \& London: University of California Press.

Statistics for Wales. 2012. 2011 Census: First results on the Welsh language. http://wales.gov. uk/docs/statistics/2012/121211sb1182012en.pdf (accessed 1 November 2012).

Statistics for Wales. 2013. Migration Statistics: Wales 2011 (Statistical Bulletin). http://wales.gov.uk/docs/statistics/2013/130312-migration-statistics-2011-en.pdf (accessed 28 February 2014). 
Thomas, Enlli Môn \& Virginia C. Mueller Gathercole. 2005. Minority language survival, obsolescence or survival in the face of English dominance. In James Cohen, Kara T. McAlister, Kelliw Rolstad \& Jeff MacSwan (eds.), ISB4: Proceedings of the 4th International Symposium on Bilingualism, 2233-2257. Somerville, MA: Cascadilla Press.

Thomas, Enlli Môn, Nia Williams, Llinos Jones \& Susi Davies. 2012. Quality and quantity of exposure: Bilingual acquisition of plural morphology in Welsh. Paper presented the International Conference in Bilingual and Multilingual interaction, Bangor University, 30 March-1 April.

Welsh Assembly Government. 2003. Iaith Pawb: A national action plan for a bilingual Wales. Cardiff: Welsh Assembly Government.

Welsh Assembly Government. 2005. Popu4001, population by age, gender and resident type: 2001 census. https://statswales.wales.gov.uk/Catalogue/Census/2001/Population-byLocalAuthority-Gender (accessed 10 October 2012).

Welsh Assembly Government. 2007. Defining schools according to Welsh-medium provision (Information document number 023/2007). Cardiff: Welsh Assembly Government.

Welsh Assembly Government. 2011. SIEQ0007: Welsh Index of Multiple Deprivation 2008. https://statswales.wales.gov.uk/Catalogue/Community-Safety-and-Social-Inclusion/ Welsh-Index-of-Multiple-Deprivation/WIMD-2008/OverallIndex-by-Area-Domain (accessed 10 October 2012).

Zeller, Richard A. \& Edward G. Carmines. 1980. Measurement in the social sciences, the link between theory and data. Cambridge: Cambridge University Press. 